\title{
Las musarañas son importantes
}

"Hay muertos que no hacen ruido, Llorona, y es más grande su penar" versa "La llorona", una de las canciones más populares dentro de la cultura mexicana. Nada más parecido a esto es el caso de las musarañas, un grupo altamente amenazado por el cambio global actual, pero más aún por el desconocimiento en torno a ellas. A pesar de su penar, muy pocos son los mastozoólogos interesados en las musarañas.

\section{Un poco sobre musarañas}

Las musarañas se caracterizan por su tamaño relativamente pequeño, ojos diminutos, hocico largo y delgado, pelaje denso y por su apetito voraz que las obliga a alimentarse constantemente y casi exclusivamente de anélidos y artrópodos, lo cual las convierte en controladores naturales de sus poblaciones (ver imagen de portada). Son parte de uno de los órdenes más diversos y ampliamente distribuidos en el planeta: el orden Eulipotyphla. Además de las musarañas (familia Soricidae), este orden también incluye a los erizos (familia Erinaceidae), topos (familia Talpidae) y solenodones (Solenodontidae). Las musarañas o sorícidos son el grupo más diverso dentro del orden Eulipotyphla (85\%; Woodman 2018), conteniendo a casi 500 especies repartidas en 25 géneros (Burgin and He, 2018). Los sorícidos se encuentran entre los linajes de mamíferos más viejos que existen y que se han adaptado a una gran variedad ambientes, desde los desiertos hasta los bosques lluviosos y la tundra.

Las musarañas también pertenecen al grupo de los mamíferos no carismáticos. Su apariencia de ratón casero, la dificultad de observarlas, y los mitos que las rodean, han provocado que la sociedad, los estudiantes e investigadores muy difícilmente se vean interesados en conocerlas y estudiarlas. En Latinoamérica el caso es incluso menos alentador. En esta región ellas se encuentran entre los mamíferos menos representados en colecciones biológicas y entre los menos estudiados. Esto es debido a la dificultad que implica tanto su captura en campo y la identificación taxonómica. En esta región, las musarañas suelen habitar regiones remotas e inhóspitas que hacen muy difícil el trabajo de campo, lo que complica la obtención de la información más básica. Antes del inicio del siglo XXI, la colecta de musarañas en Latinoamérica podría definirse como contingente, debido a su colecta accidental al tratar de muestrear diversas especies de roedores. Hoy en día, algunas especies aún se conocen solo de la localidad tipo (e. g., Sorex stizodon) o no han sido colectadas nuevamente durante varias décadas (e. g., Sorex sclateri). En contraparte están las que apenas están siendo descubiertas y descritas, como los casos de C. lacandonensis, C. dinirensis y C. monteverdensis; otras probablemente están en el camino de la extinción debido a actividades humanas. Ante el notable vacío de información sobre su distribución y diversidad actual, no ha sido posible realizar una adecuada valoración del estado de conservación de la mayoría de especies de musarañas en Latinoamérica.

\section{Lo que falta}

Yo empecé a estudiar musarañas en México hace cerca de 15 años, gracias a la iniciativa del curador de la Colección Nacional de Mamíferos del Instituto de Biología de la UNAM, Fernando A. Cervantes. Con el esfuerzo de estudiantes de licenciatura, maestría y doctorado, durante este tiempo hemos realizado trabajo de campo, revisión de ejemplares en colección, depuración de bases de datos y estudios de taxonomía, sistemática y biogeografía de especies principalmente mexicanas. No tengo duda que se ha avanzado en su conocimiento, pero también debo reconocer con profunda pena que todavía no ha sido lo esperado. Aun existen pocos, muy pocos estudiantes interesados en el estudio de musarañas a largo plazo, lo que se refleja en pocas publicaciones científicas. En los Congresos bianuales que organiza la Asociación Mexicana de Mastozoología A. C., son pocas o a veces nulas las presentaciones que abarcan algún aspecto de las musarañas. Simplemente, no hay un club de "musarañólogos". Echar a andar este fascículo especial sobre musarañas es un claro ejemplo de lo mucho que aun falta por promover el estudio de estos mamíferos pequeños.

A pesar de todo esto, aquí estamos, intentado dar a conocer un poco más acerca de este grupo fascinante de mamíferos. La intención de este número especial va más allá de generar y compartir este conocimiento, sino para inspirar a las nuevas generaciones de jóvenes mastozoólogos para que inviertan su tiempo, esfuerzo y corazón, en estudiar grupos extraordinariamente diversos pero muy poco atendidos en nuestra región, tal como las musarañas. ¿Oportunidades? Muchas. Por ejemplo, debido a que son altamente vulnerables al cambio global, tal como los efectos asociados con la destrucción del hábitat y por el cambio climático, son un grupo idóneo para evaluar el efecto potencial de las actividades antropogénicas en la biodi- 
versidad (Scholss et al. 2011; Guevara et al. 2015). Por otro lado, la importancia de las musarañas en interacciones hospedero-parásito está aún en pleno desarrollo en la región. Los estudios de anatomía y fisiología son prácticamente nulos, por lo que aun desconocemos el potencial de estas especies para adaptarse a las presiones que ejerce el mundo actual sobre los ecosistemas. El trabajo de campo hacia lugares poco explorados muy probablemente arrojará luz nueva sobre los patrones de distribución, así como sobre la variación genética y fenotípica en poblaciones naturales. Estos son solo algunos ejemplos que, desde mi perspectiva, ofrecen un oportunidad inigualable para estudiar aspectos básicos, pero prioritarios en nuestra región.

\section{Agradecimientos}

Agradezco a todos los autores invitados que están participando con sus contribuciones, ya que ustedes son parte crucial de este esfuerzo noble de dar a conocer un poco más sobre las musarañas. En el plano más personal e íntimo, agradezco a todas personas que viven en la Latinoamérica de hoy y que, a pesar de las dolencias y "carencias", nos han abierto sus puertas en los lugares más remotos para que podamos pernoctar, dejar nuestro equipo de campo o simplemente pasar a beber un poco de agua o una taza de café mientras hemos estado en busca de musarañas. Todas esas personas nos han ayudado a ver las verdaderas riquezas con las que cuenta nuestra región, más allá de las musarañas.

\section{Literatura citada}

BuRGIN, C. J., AND K. HE. 2018. Family Soricidae (Shrews). Pp. 332- 551 in: Handbook of the Mammals of the World (Wilson, D. E., and R. A. Mittermeier, eds.). . Vol. 8. Insectivores, Sloths and Colugos. Lynx Editions. Barcelona, Spain.

Guevara, L., F. A . Cervantes, And V. Sánchez-Cordero. 2015. Riqueza, distribución y conservación de los topos y las musarañas (Mammalia, Eulipotyphla) de México. Therya 6:43-68.

Schloss, C. A., T. A. Nuñez, AND J. J. Lawler. 2011. Dispersal will limit ability of mammals to track climate change in the Western Hemisphere. Proceedings of the National Academy of Sciences 109:8606-8611.

WoOdman, N. 2018. American Recent Eulipotyphla: Nesophontids, Solenodons, Moles, and Shrews in the New World. Smithsonian Contributions to Zoology 650. Washington, U.S. A.

LÁZARO GUEVARA Departamento de Zoología, Instituto de Biología, Universidad Nacional Autónoma de México. Av. Universidad 3000, Circuito Exterior S/N Coyoacán, CP. 04510, Ciudad de Mexico Mexico. Email:Ig@ib.unam.mx 